\title{
Dispelling the nice or naughty myth: retrospective observational study of Santa Claus
}

\author{
John J Park,, Ben G T Coumbe, ${ }^{2}$ Esther H G Park, ${ }^{3}$ George Tse, ${ }^{4}$ S V Subramanian, ${ }^{5}$ Jarvis T Chen ${ }^{5}$
}

${ }^{1}$ Harvard TH Chan School of

Public Health, 677 Huntington

Ave, Boston 02115, MA, USA

2University College London

Medical School, Royal Free

Hospital, London, UK

3University of Edinburgh

Medical School, Edinburgh, UK

${ }^{4}$ Department of Radiology,

Sheffield Teaching Hospitals

NHS Foundation Trust, Northern General Hospital, Sheffield, UK

${ }^{5}$ Department of Social and

Behavioral Sciences, Harvard TH

Chan School of Public Health,

Boston. MA, USA

Correspondence to: J J Park john.park@mail.harvard.edu

Cite this as: BMJ 2016;355:16355 http://dx.doi.org/10.1136/bmj.i6355

Accepted: 22 November 2016

\section{ABSTRACT}

OBJECTIVE

To determine which factors influence whether Santa Claus will visit children in hospital on Christmas Day. DESIGN

Retrospective observational study.

SETTING

Paediatric wards in England, Northern Ireland, Scotland, and Wales.

\section{PARTICIPANTS}

186 members of staff who worked on the paediatric wards ( $n=186)$ during Christmas 2015.

\section{MAIN OUTCOME MEASURES}

Presence or absence of Santa Claus on the paediatric ward during Christmas 2015. This was correlated with rates of absenteeism from primary school, conviction rates in young people (aged 10-17 years), distance from hospital to North Pole (closest city or town to the hospital in kilometres, as the reindeer flies), and contextual socioeconomic deprivation (index of multiple deprivation).

\section{RESULTS}

Santa Claus visited most of the paediatric wards in all four countries: $89 \%$ in England, 100\% in Northern Ireland, $93 \%$ in Scotland, and $92 \%$ in Wales. The odds of him not visiting, however, were significantly higher for paediatric wards in areas of higher socioeconomic deprivation in England (odds ratio 1.31 (95\% confidence interval 1.04 to 1.71) in England, 1.23 (1.00 to 1.54) in the UK). In contrast, there was no correlation with school absenteeism, conviction rates, or distance to the North Pole.

\section{CONCLUSION}

The results of this study dispel the traditional belief that Santa Claus rewards children based on how nice or naughty they have been in the previous year. Santa Claus is less likely to visit children in hospitals in the most deprived areas. Potential solutions include a review of Santa's contract or employment of local Santas in poorly represented regions.

\section{Introduction}

Santa Claus (also known as Saint Nicholas, St Nick, Father Christmas, Kris Kringle, Santy, or simply Santa)

\section{WHAT IS ALREADY KNOWN ON THIS TOPIC}

It has long been believed that Santa Claus visits children who have been well behaved

\section{WHAT THIS STUDY ADDS}

This study dispels the myth that Santa Claus visits children based on behaviour in the previous year

Socioeconomic deprivation seems to play a greater role in determining a visit by Santa Claus, with children in hospitals in the most deprived areas less likely to receive a visit is a popular Christmas figure celebrated for travelling around the world to give children presents on Christmas Day (25 December).

It has long been thought that Santa Claus visits children depending on whether they have been naughty or nice in the past year (fig 1). This belief finds textual support in the popular holiday song "Santa Claus is coming to Town," written by Fred Coots and Haven Gillespie and published in 1934. ${ }^{1}$ The Christmas classic goes on: "he sees when you're sleeping, he knows when you're awake, he knows if you've been bad or good, so be good for goodness sake!" Yet no empirical evidence exists to support the assertion that Santa Claus rewards children based on good behaviour or to establish whether this is the only factor determining the likelihood of a visit from him. ${ }^{2}$ We chose to study paediatric hospital wards because sick children are the most deserving of a visit from Santa Claus at Christmas. We evaluated the relative importance of children's behaviour, distance to the North Pole, and contextual socioeconomic deprivation on the likelihood of a visit from Santa Claus.

\section{Methods}

\section{Outcomes}

Because auditing departments close over Christmas, hospitals hold no records on visits by Santa Claus. Therefore we telephoned every UK hospital with a paediatric ward (obtained from the Royal College of Paediatrics and Child Health) and asked the ward staff to identify someone who worked on Christmas Day 2015 and could attest to a visit by Santa Claus. We recorded the name and position of the witness and whether or not Santa Claus had visited. We also collected additional information about other superheroes who visited the ward on this festive occasion. Data collection occurred in July and August 2016.

\section{Determinants}

We used the website FreeMapTools (www.freemaptools.com) to record the distance $(\mathrm{km})$ between the hospital (closest city or town to the hospital) and North Pole, as the reindeer flies. We considered two sources of data as potential indicators of naughtiness. Firstly, rates of absenteeism from primary school as a proxy for child behaviour were obtained from national government databases in 2015, available online for each respective country (England, ${ }^{3}$ Scotland, ${ }^{4}$ Northern Ireland, ${ }^{5}$ and Wales $^{6}$ ) and regions within England. School absenteeism was defined by the total number of authorised and unauthorised absences, counted in sessions where each session is equivalent to half a day. Secondly, we obtained data from the Ministry of Justice on the conviction rate for crimes by young people per 1000 of the 10-17 year old 


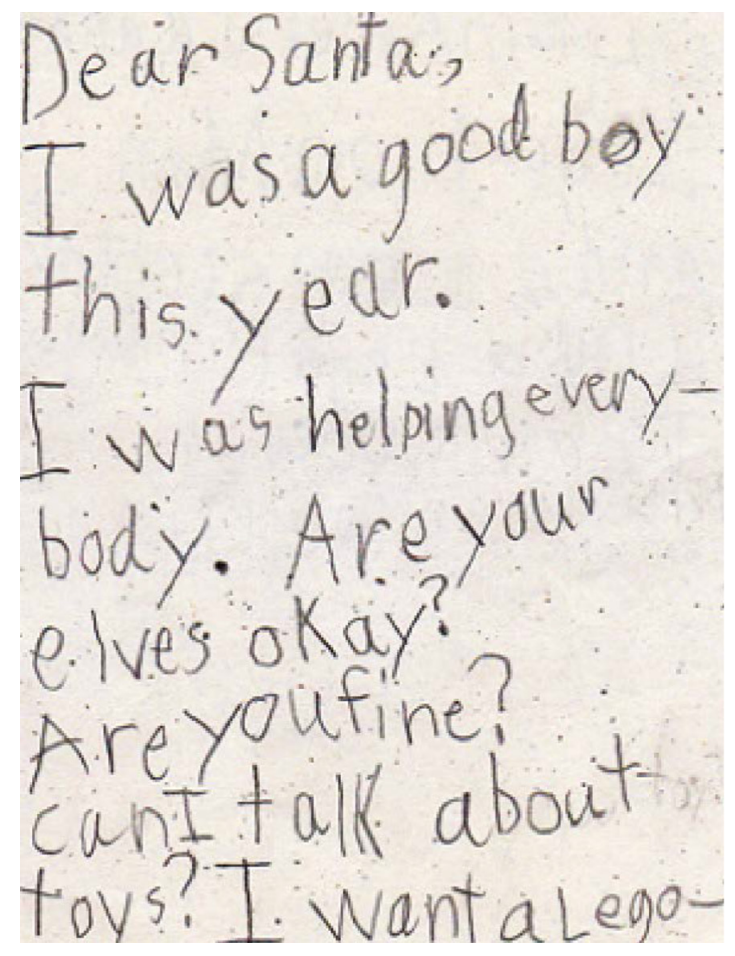

Fig 1 | Many children believe that Santa Claus rewards good behaviour. Written by Fred, aged 7

\begin{tabular}{|c|c|c|c|}
\hline Covariates & Mean (SD) & Minimum & Maximum \\
\hline School absenteeism (\% of total) & $4.3(0.37)$ & 3.9 & 5.1 \\
\hline Conviction rate per 1000 10-17 year olds* & $18.7(7.7)$ & 7.1 & 31.1 \\
\hline Distance to North Pole & 4151 (177.9) & 3602 & 4416 \\
\hline Index of multiple deprivationt & $5.5(2.5)$ & 1 (least deprived) & 10 (most deprived) \\
\hline
\end{tabular}

\begin{tabular}{|c|c|c|c|}
\hline National/regional areas & $\begin{array}{l}\text { No of wards } \\
\text { visited }\end{array}$ & $\begin{array}{l}\text { Total No } \\
\text { of wards }\end{array}$ & $\begin{array}{l}\text { Percentage } \\
\text { visited }\end{array}$ \\
\hline England & 135 & 151 & 89.4 \\
\hline Northern Ireland & 8 & 8 & 100.0 \\
\hline Scotland & 14 & 15 & 93.3 \\
\hline Wales & 11 & 12 & 91.7 \\
\hline \multicolumn{4}{|l|}{ English regions: } \\
\hline East Midlands & 8 & 9 & 88.9 \\
\hline Eastern England & 16 & 17 & 94.1 \\
\hline Kent, Surrey, and Sussex & 12 & 13 & 92.3 \\
\hline North central and east London & 12 & 13 & 92.3 \\
\hline North east & 3 & 6 & 50.0 \\
\hline North west & 22 & 23 & 95.7 \\
\hline North west London & 5 & 7 & 71.4 \\
\hline South London & 10 & 10 & 100.0 \\
\hline South west & 9 & 11 & 81.8 \\
\hline Thames Valley & 5 & 5 & 100.0 \\
\hline Wessex & 8 & 8 & 100.0 \\
\hline West Midlands & 12 & 14 & 85.7 \\
\hline Yorkshire and the Humber & 13 & 15 & 86.7 \\
\hline
\end{tabular}

population. ${ }^{7}$ Data were unavailable for Kent, Surrey, Sussex, Thames Valley, Wessex, Northern Ireland, and Scotland. For regions within London we assigned values based on the conviction rate for ages 10-17 years in all of London. Contextual socioeconomic deprivation was characterised by the index of multiple deprivation, which combines data on seven domains of deprivation: income, employment, health deprivation and disability, education skills and training, barriers to housing and services, crime, and living environment, as calculated by each of the four countries. ${ }^{8-11}$ Each hospital was assigned a score based on the decile ranking of the area in which it is located. Since publically available index of multiple deprivation deciles in Wales are classed into broader categories (deciles 1, 2, 3-5, 6-10), paediatric wards in Wales were assigned to the midpoint of their deprivation category. We carried out subanalyses restricted to regions within England, and for analyses involving conviction data to selected regions within England as well as Wales. Table 1 presents the summary statistics for the determinants.

For modeling purposes we reversed the coding of the deprivation variable (making 10 most deprived and 1 least deprived) so that our odds ratios could be interpreted in relation to the effect of increased deprivation on the odds of Santa's visit.

\section{Statistical analyses}

We calculated the proportions of paediatric wards visited by Santa Claus for each of the four countries and for regions within England (table 2). Fisher's exact test was used to detect differences between areas in the likelihood of visits.

To explore associations between school absenteeism, conviction rates in young people, distance to North Pole, and contextual socioeconomic deprivation, we fit logistic regression models for the odds of no visit by Santa Claus, with each predictor modeled linearly. To evaluate potential regional clustering, we fit logistic mixed effect models with random regional effects but found no evidence of a statistically significant component for regional variance. Accordingly, the results of the models are reported based on traditional logistic regression models (table 3 ). All analyses were conducted in R. ${ }^{12}$

\section{Patient involvement}

No patients were involved in setting the research question or the outcome measures, nor were they involved in developing plans for recruitment, design, or implementation of the study. No patients were asked to advise on interpretation or writing up of results. There are no plans to disseminate the results of the research to study participants or the relevant patient community.

\section{Results}

Santa Claus visited 168 (90\%) of the 186 paediatric hospital wards in the UK. Of the original 191 paediatric wards obtained from the Royal College of Paediatrics and Child Health, we excluded five. Of those five 


\begin{tabular}{|c|c|c|c|c|c|}
\hline Variables & Estimate & SE & $z$ value & $P$ value & Odds ratio $(95 \% \mathrm{Cl})$ \\
\hline School absenteeism (\% of total) & 0.040 & 0.661 & 0.060 & 0.952 & $1.04(0.26$ to 3.59$)$ \\
\hline Distance to North Pole (per 100 km) & -0.051 & 0.135 & -0.384 & 0.701 & $0.95(0.74$ to 1.26$)$ \\
\hline School absenteeism (\% of total) & 1.053 & 1.003 & 1.049 & 0.294 & $2.86(0.35$ to 19.04$)$ \\
\hline Distance to North Pole (per 100 km) & -0.332 & 0.203 & -1.632 & 0.103 & $0.72(0.48$ to 1.07$)$ \\
\hline IMD decile & 0.272 & 0.126 & 2.163 & 0.031 & 1.31 (1.04 to 1.71$)$ \\
\hline \multicolumn{6}{|l|}{ Selected regions and Wales*: } \\
\hline Conviction rate per 1000 10-17 year olds & 0.000 & 0.034 & 0.002 & 0.999 & $1.00(0.93$ to 1.07$)$ \\
\hline
\end{tabular}

IMD =index of multiple deprivation.
* Regions excluded were Kent, Surrey, Sussex, Thames Valley, Wessex (crime data measure rates in following areas: East Midlands, eastern England,
London, north east, north west, south east, south west, Wales, West Midlands, Yorkshire), Northern Ireland, and Scotland.

London, north east, north west, south east, south west, Wales, West Midlands, Yorkshire), Northern Ireland, and Scotland.

(all in England), staff of one ward declined to answer and four wards had closed or been transferred to another hospital.

All eight of the paediatric wards in Northern Ireland were visited by Santa Claus, representing the most successful coverage of visits by Santa. Scotland achieved second place, with 93\% coverage (14/15 wards), and Wales came third with $92 \%$ coverage (11/12 wards). Notably, the proportion of wards visited in Northern Ireland, Scotland, and Wales was higher than the $89 \%$ (135/151 wards) visited in England (although relatively smaller numbers of paediatric wards led to Fisher's exact P values of 0.42 for Northern Ireland, 0.53 for Scotland, and 0.64 for Wales compared with England) (table 2). Within England, regional variation was observed in the proportion of paediatric wards visited (from a minimum of $50 \%$ in the north east to $100 \%$ in south London, Thames Valley, and Wessex, fig 2). The low proportions of paediatric wards visited in the north east (50\%) and in north west London $(71 \%)$ point to the need for urgent corrective action by Santa Claus.

\section{Naughty or nice?}

Based on the results of logistic regression models summarised in table 3, regional rates of school absenteeism were not statistically significantly associated with the odds of no visit by Santa Claus in either the full UK analysis or the England subanalysis, although the point estimate in the England subanalysis was substantially higher than in the UK analysis. Furthermore, we found no association between conviction rates in young people and visits from Santa Claus in the subanalysis of English regions and Wales.

Distance between hospital and North Pole In neither the UK analysis nor England subanalysis did distance $(\mathrm{km})$ of hospital to the North Pole have a statistically significant effect on whether Santa Claus would or would not visit a paediatric ward (table 3).

\section{Contextual socioeconomic deprivation}

In the UK analysis, the index of multiple deprivation was marginally associated with the odds of not being visited by Santa Claus: a 1 unit change in the index of multiple deprivation decile from least deprived to most deprived was associated with a 1.23 times increase in the odds of not being visited by Santa Claus (95\% confidence interval 1.00 to $1.54, \mathrm{P}=0.06$ ). In the England subanalysis, the odds ratio for a 1 unit change in the index of multiple deprivation decile was 1.31 (1.04 to 1.71 , $\mathrm{P}=0.03)$. We also explored the relation between index of multiple deprivation decile and proportion of visits (fig 3). A generally decreasing pattern of visits was observed with increasing deprivation across the top five deciles (1-5) of deprivation, with only $79 \%$ of paediatric wards in the fifth decile reporting visits. The pattern of visits varied across the bottom five deciles (6-10), with all showing fewer visits than the top four deciles (1-4).

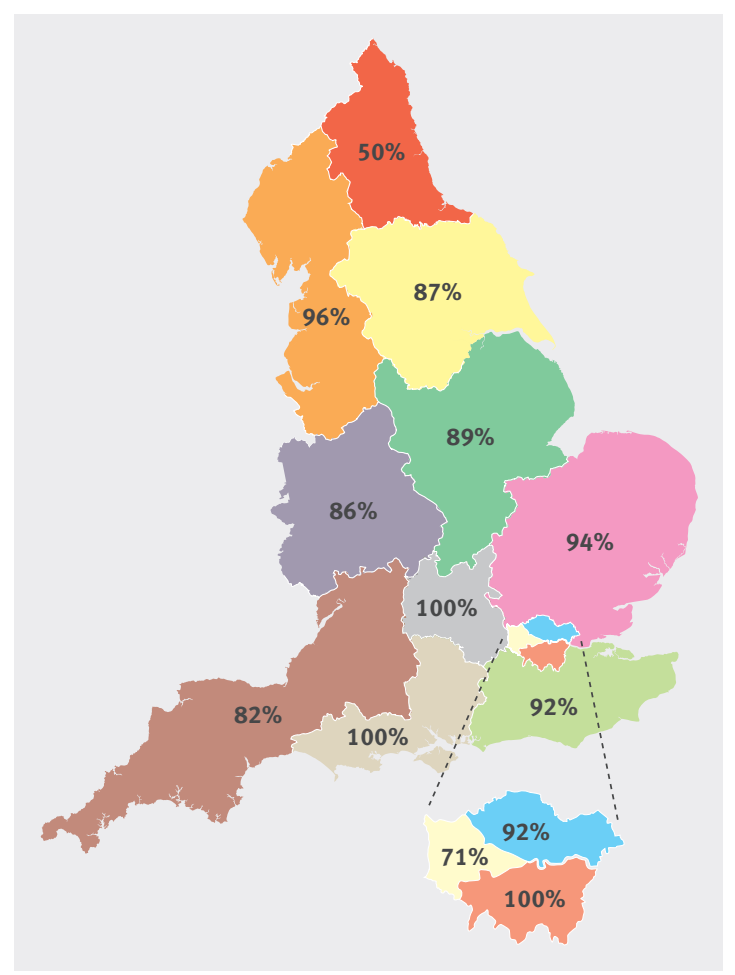

Fig 2 | Regional variations in visits by Santa Clause in England, 2015 


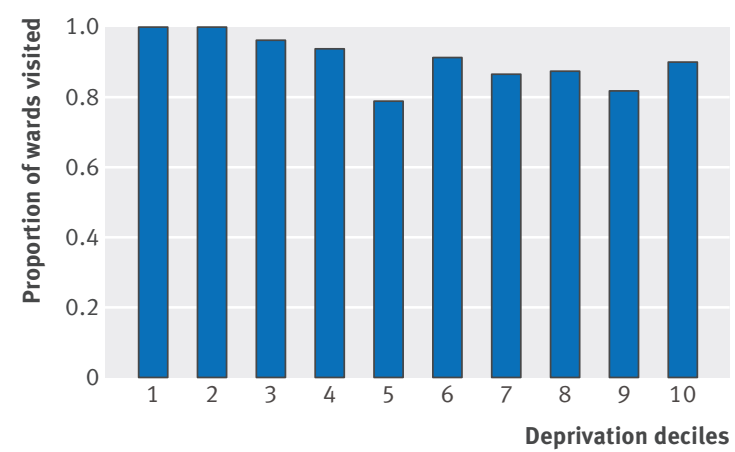

Fig 3 | Proportion of paediatric hospital wards visited by Santa Claus according to deprivation, 2015. Deprivation deciles from 1 (least deprived) to 10 (most deprived)

\section{Local superheroes}

Santa Claus was not the only non-clinical visitor to the paediatric wards on Christmas Day. Twenty three different fictional and non-fictional characters also brought festive cheer. Of those, the most popular were elves, followed by footballers, pantomime characters, and clowns. Elsa (from the animated movie, Frozen) was joint fifth with firemen (fig 4).

\section{Discussion}

Our findings do not support the widely accepted belief that Santa Claus only visits children who are nice. ${ }^{13}$ Dispelling the "naughty or nice" myth has important implications, including a possible increase in outbursts of bad behaviour by children over Christmas if they find out. This raises the important ethical question: should children be told about this?

Our most important finding is that Santa Claus is less likely to visit hospitals in deprived areas. Of note was the significant association of visits with index of multiple deprivation decile in England $(\mathrm{P}=0.03)$. One possible reason for the weaker association observed in the UK analysis $(\mathrm{P}=0.056)$ is that the index of multiple deprivation is calculated and summarised differently in each of the four countries. A nation specific index of multiple deprivation is preferred for policy, planning, and resource allocation as it is sensitive to each nation's

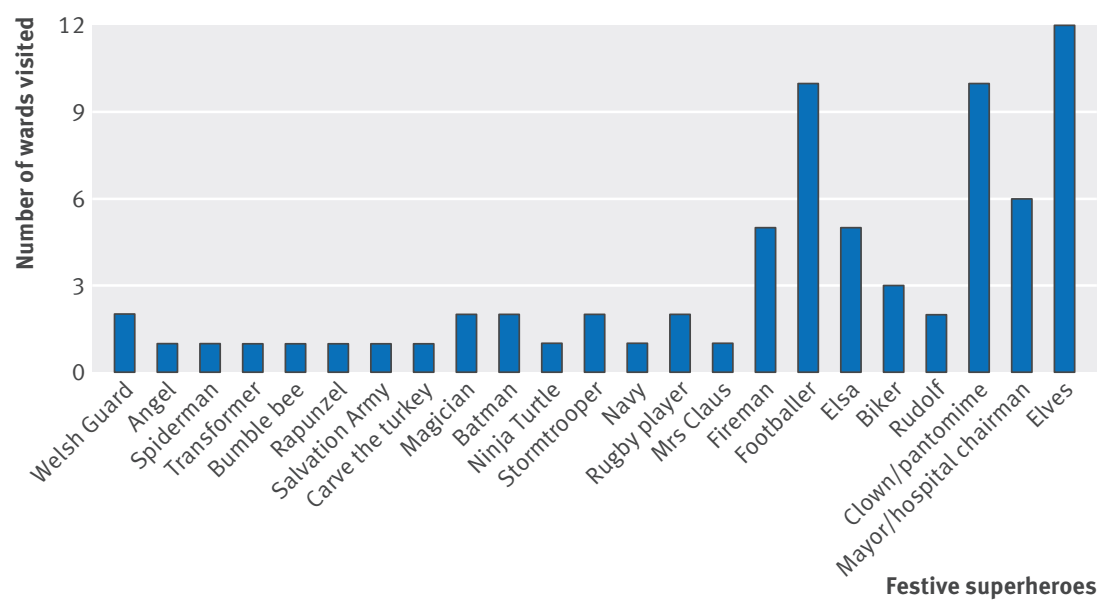

Fig 4 | Local superheroes who also spread festive cheer on paediatric wards, 2015 unique patterns of deprivation, but future analyses of Santa's visitation patterns in relation to contextual deprivation across the UK would benefit from a consistent and comparable deprivation metric. ${ }^{14}$

A surprising finding was that Santa Claus does not discriminate against children based on country or region (for example, we hypothesised that he would prefer to visit Wales and Scotland owing to these countries seemingly more habitable climates for reindeers). Indeed this study shows that distance from the North Pole was not a factor that influenced whether Santa Claus visited a hospital and confirms the widely held belief that he is not limited by distance or time and is capable of delivering gifts across the globe within a 24 hour period..$^{15}$

It is the authors' anecdotal experience that children rarely voluntarily admit to being naughty. Our study therefore included two potential indicators of child naughtiness: regional primary school absenteeism and conviction rates in young people. Neither is ideal as they are measured at a relatively coarse level of geographical aggregation, and in the case of conviction rates are subject to uneven reporting across the regions. The fact that we found no significant associations with either indicator suggests that the "nice or naughty" myth can be dispelled, but future research should attempt to obtain better individual level estimates of naughtiness in children to confirm this finding. We must also acknowledge the limitations of these ecological variables: we would hope that Santa Claus makes his decisions to visit sick children in hospital independent of the naughtiness of other children in the region. There are also other potential predictors of his visits that could not be included in our analysis. For example, despite the authors' best efforts, information on the size and characteristics of paediatric wards was not available for further analysis of the data. A response to the authors' freedom of information request to NHS England was that this information was not available. We also caution that although our study shows that Santa Claus is less likely to visit paediatric wards in more deprived areas, we cannot conclude from our correlational study why this association exists. Finally, other variables such as the quality of whisky left for him in hospitals, availability of Christmas dinners, ${ }^{16}$ availability of chimneys, and free NHS parking spaces for reindeers may need to be explored. Whether Santa Claus actively discriminates or whether deeper structural factors are at play needs to be examined through further studies.

Why do children in the most deprived areas have it worse? One possible theory is that Santa Claus is forced to sustain existing inequality, as he is contractually not allowed to change anyone's socioeconomic status. ${ }^{17}$ Giving children presents beyond their economic means might result in Santa Claus gaining political power and thereby causing widespread discontent. This would run directly contrary to the primary mission statement of the North Pole: the deliverance of cheer.

Finally, the authors (and the hospital staff who participated in the survey) salute the local heroes and visitors who devote their time to visiting sick children in 
hospital over Christmas. Even if Santa Claus does not reach all areas equally, this is counterbalanced by the work of these local heroes, who do a wonderful job spreading good cheer to sick children, naughty or nice. Surprisingly, the most popular visitors apart from Santa Claus were elves and not Elsa!

\section{Conclusion}

It has long been thought that Santa Claus gives presents to nice but not naughty children. This is the first study, to our knowledge, to dispel the myth that Santa visits children based on behaviour and suggests socioeconomic deprivation plays a greater role in determining a visit. It raises important ethical dilemmas, such as whether children should be told and what should be done about Santa.

Santa Claus has an incredibly tough job to ensure that all the nice children receive presents. Undoubtedly deeper socioeconomic factors are at play, even impacting Santa Claus's abilities to reach out to every child. Whether his contract needs to be reviewed or local Santas employed in "hard to reach" areas, all we want is for every child to be happy this Christmas.

Contributors: JP conceived the study. JP and GT designed the study. BC, EP, and JP collected the data. JP, SVS, and JTC analysed the data. All authors contributed to the drafting and editing of the manuscript. JP is the guarantor.

Funding: This study was not funded or sponsored by industry and follows guidelines on good publication practice.

Competing interests: All authors have completed the ICMJE uniform disclosure form at www.icmje.org/coi disclosure.pdf and declare: no support from any organisation for the submitted work; no financial relationships with any organisations that might have an interest in the submitted work in the previous three years; no other relationships or activities that could appear to have influenced the submitted work.

Ethical approval: A full submission for ethical approval using the integrated research application system was not required since the study did not involve "any modification of investigation, treatment or other aspects of clinical practice," or involve "potentially physically or mentally invasive procedures on volunteers." All participants gave informed consent before taking part in the questionnaire study. Data sharing: No additional data available.

Transparency: The guarantor (JP) affirms that the manuscript is a honest, accurate, and transparent account of the study bring reported; that no important aspects of the study have been omitted; and that any discrepancies from the study as planned (and, if relevant, registered) have been explained.
This is an Open Access article distributed in accordance with the Creative Commons Attribution Non Commercial (CC BY-NC 3.0) license, which permits others to distribute, remix, adapt, build upon this work non-commercially, and license their derivative works on different terms, provided the original work is properly cited and the use is non-commercial. See: http://creativecommons.org/licenses/ by-nc/3.0/.

1 ASCAP Unwraps the Top 30 Holiday Songs of the Century. American Society Of Composers, Authors And Publishers. Accessed 31 August 2016. www.ascap.com/ press/2014/1203-top-holiday-songs-100-years

2 Fischer D. Has Santa Claus a Good Long-Term Memory? Social Science Research Network. Accessed 31 August 2016. http://papers.ssrn. $\mathrm{com} / \mathrm{sol} 3 /$ papers.cfm?abstract id $=1400614$

3 National Statistics. Pupil absence in schools in England: 2014 to 2015. Department for Education. UK Government. Accessed 31 August 2016. www.gov.uk/government/statistics/ pupil-absence-in-schools-in-england-2014-to-2015

4 High Level Summary of Statistics Trend. School Attendance. Scottish Government. Accessed 31 August 2016. www.gov.scot/Topics/ Statistics/Browse/School-Education/TrendSchoolAttendance

5 Attendance at grant-aided primary, post-primary and special schools in Northern Ireland: 2014/15. Summary statistics. Department of Education. Northern Ireland Executive. Accessed 31 August 2016. www.education-ni.gov.uk/sites/default/files/publications/de/ attendance-at-grant-aided-primary-post-primary-and-specialschools-in-northern-ireland-2014-15-summary-statistics.pdf

6 Absenteeism from Primary Schools. 2014/2015. Welsh Government. Accessed 31 August 2016. http://gov.wales/statistics-and-research/ absenteeism-primary-schools/?lang=en

7 Ministry of Justice. UK. Youth Justice Annual Statistics: 2014 to 2015. Accessed 11 November 2016. www.gov.uk/government/statistics/ youth-justice-annual-statistics-2014-to-2015

8 Scottish Index of Multiple Deprivation. Interactive Map. Scottish Government. Accessed 30 August 2016. www.gov.scot/Topics/ Statistics/SIMD/SIMDInteractive

9 Wales Index of Multiple Deprivation. Welsh Government. Accessed 30 August 2016. http://wimd wales.gov.uk/

10 Northern Ireland Multiple Deprivation Measure. 2010. Northern Ireland Statistics and Research Agency. Accessed 30 August 2016. www.nisra.gov.uk/deprivation/nimdm_2010.htm

11 Official Statistics. English indices of deprivation 2015. Department fo Communities and Local Government. UK Government. Accessed 30 August 2016. www.gov.uk/government/statistics/ english-indices-of-deprivation-2015

12 R Core Team. (2016). R: A language and environment for statistical computing. R Foundation for Statistical Computing, Vienna, Austria. www.R-project.org/.

13 Wilcock DA. Santa's Christmas Visit: A Three Boys Adventure. West London Books, 2013.

14 Payne RA, Abel GA. UK indices of multiple deprivation - a way to make comparisons across constituent countries easier. Health Stat $Q$ 2012;53.

15 Official NORAD Santa Tracker. Accessed 31 August 2016. www. noradsanta.org/

16 Gosnell EJ. Christmas dinner for doctors on duty: it's grimmer up north. BMJ 2014;349:g7269. doi:10.1136/bmj.g7269.

17 Christmas Why Does Santa Give Rich Kids More? Accessed 31 August 2016. www.reddit.com/r/AskScienceFiction/comments/3xzgur/ christmas_why_does_santa_give_rich_kids_more/ 